\title{
Comparison between percutaneous vertebroplasty and percutaneous kyphoplasty in the treatment of posterior wall rupture and osteoporotic vertebral compression fractures-Case - based retrospective study
}

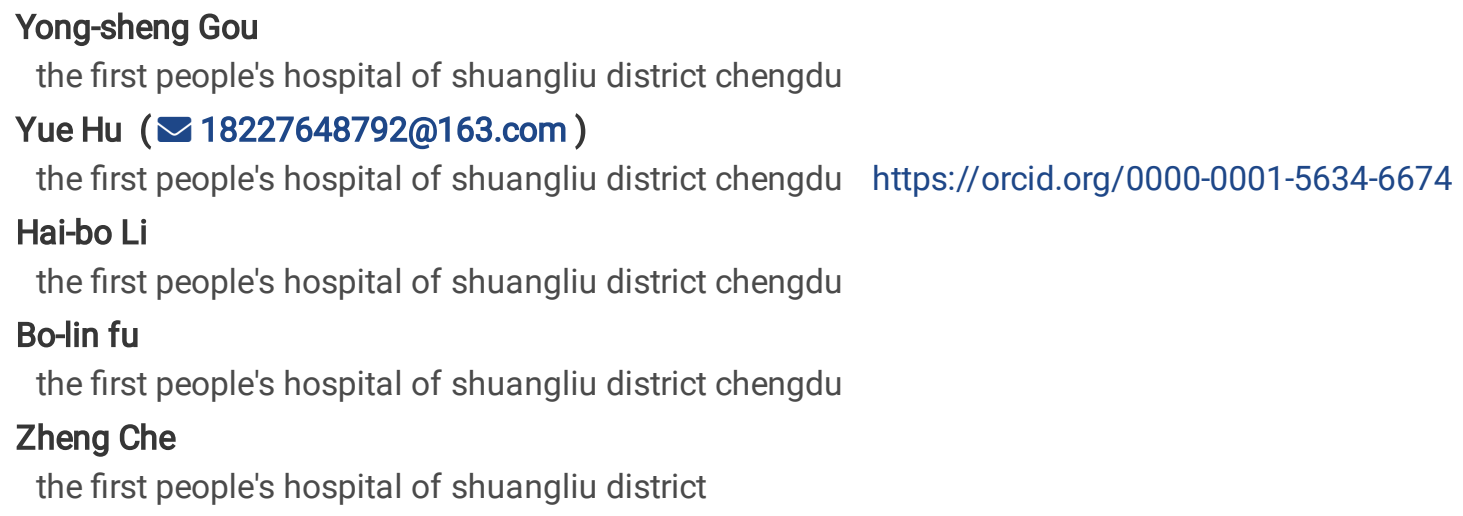




\section{Abstract}

Background: Percutaneous kyphoplasty (PKP) or percutaneous vertebral plasty (PVP) has been widely applied in the treatment of osteoporotic vertebral compression fractures (osteoporotic vertebral compression will fracture, OVCF) because of its minimally invasive and effective. To compare the clinical efficacy and safety of percutaneous vertebroplasty versus percutaneous kyphoplasty for osteoporotic vertebral compression fractures with posterior wall broken.

Methods: 82 patients with osteoporotic vertebral compression fracture with posterior wall broken were divided into PVP group(group A) and PKP group(group B) \The operation time, perspective times, bone cement volume injected. cement leakage, hospitalization expenses, preoperative visual analog score(VAS) and Oswestry disability index(ODI), restoration height of vertebral, the vertebrae height loss and new fracture of adjacent vertebra were evaluated during the follow-up.

Results: The PVP group incurred significantly shorter operation time $(40.37 \pm 8.26 \mathrm{~min})$ and less perspective times $(22.23 \pm 3.79$ times)than the PKP group(46.74 \pm 9.58 min and $27.96 \pm 5.71$ times respectively) $(P<0.05)$. The PVP group incurred significantly less expenses than the PKP group $(P<0.05)$. The VAS scores and ODI at 1 day and 6 months post-operation were significantly lower than pre-operation in both groups $(P<0.05)$.

Conclusion: Both PVP and PKP Can obtain satisfactory clinical efficacy for the treatment of osteoporotic vertebral compression fractures with posterior wall broken,but the former may have advantages of less expenses,shorter operation time.

Trial registration: This retrospective study was approved by the ethics committee of the first people's hospital of shuangliu district, Chengdu, Moreover, this study was also registered in the Chinese clinical trial registry with the registration number of ChiCTR1900028176.

\section{Background And Data}

Percutaneous kyphoplasty (PKP) or percutaneous vertebral plasty (PVP) has been widely applied in the treatment of osteoporotic vertebral compression fractures (osteoporotic vertebral compression will fracture, OVCF) because of its minimally invasive and effective. However, for the injured vertebra wall broken after osteoporotic vertebral compression fractures, due to the increased risk of bone cement leakage into the spinal canal, two kinds of treatment methods for clinical effect assessment after treatment have been reported rarely in clinical practice. 82 cases of OVCF patients admitted to our hospital from March 2012 to June 2018 were treated respectively with percutaneous kyphoplasty (PKP) or percutaneous vertebroplasty. The clinical efficacy is as follows.

\section{Methods}

1.1 clinical data

\subsection{1 inclusion and exclusion criteria}

1) inclusion criteria: patients over the age of 60 who were diagnosed with fresh osteoporotic thoracolumbar compression fracture with vertebral posterior wall breakage (all patients received percutaneous kyphoplasty after CT scan confirmed fractured vertebral posterior wall breakage or partial fracture and then transferred into spinal canal less than $1 / 3$ sagittal diameter of spinal canal); 2 ) exclusion criteria: (1) primary or metastatic bone tumor, 2 vertebral bodies without painful osteoporotic thoracolumbar vertebral compression fractures, (3) multiple segmental thoracolumbar fracture, (4) the nerve injury, (5)the combining rear ligament complex injury, (6)follow-up time is less than 6 months after treatment.

\subsection{2 case data}

This study included 82 patients, who were divided into two groups A and B according to different surgical methods. Group A: percutaneous kyphoplasty group (PVP); group B: percutaneous kyphoplasty group (PKP). There were 40 patients in group $A$, including 12 males and 28 females. The mean age was $71.47 \pm 5.33$ years old. The time from injury to operation was $2 \sim 20$ days $(4.35 \pm 2.41)$ on average. Follow-up time: 8 to 24 months, average $12.39 \pm 2.57$ months. Fracture vertebral distribution: T7 I cases, T8 I cases, T9 2 cases, T10 1 case, T11 5 cases, T12 11 cases, L1 9 cases, L2 6 cases, L3 2 cases, L4 2 cases. There were 42 
patients in group $B$, including 12 males and 30 females. The mean age was $72.79 \pm 7.59$ years. The time from injury to operation was $1 \sim 20$ days $(4.53 \pm 2.19)$ on average. Follow-up time: 8 to 25 months, average $12.88 \pm 4.27$ months. Fracture vertebral distribution: T6 I cases, T8 I cases, T9 1 cases, T10 2 cases, T11 6 cases, T12 12 cases, L1 8 cases, L2 7 cases, L3 2 cases, L4 2 cases. There was no significant difference in age, gender, fracture vertebral distribution, injury distance from surgery, and follow-up time between the two groups $(P>0.05)$. The two groups were comparable.(Table1)

Table 1

Comparison of general information between group $A$ and group $B$

\begin{tabular}{|c|c|c|c|c|c|}
\hline Characteristics & & A & B & $x^{2}$ & $P$ \\
\hline \multirow[t]{2}{*}{ Age(year) } & $\otimes 70$ & $18(45.00)$ & $20(47.62)$ & 0.361 & 0.859 \\
\hline & $\geq 70$ & $22(55.00)$ & $22(52.38)$ & & \\
\hline \multirow[t]{2}{*}{ gender } & Male & 12(30.00) & 13(30.95) & 0.835 & 0.672 \\
\hline & Female & $28(70.00)$ & $29(69.05)$ & & \\
\hline \multirow[t]{2}{*}{ fracture vertebral distribution } & thoracic & $21(52.50)$ & $23(54.76)$ & 1.615 & 0.721 \\
\hline & lumbar vertebra & $19(47.50)$ & $19(45.24)$ & & \\
\hline \multirow[t]{2}{*}{ injury distance from surgery (days) } & $\otimes 7$ & $28(70.00)$ & $30(71.43)$ & 1.719 & 0.713 \\
\hline & $\geq 7$ & $12(30.00)$ & $12(28.57)$ & & \\
\hline \multirow[t]{2}{*}{ follow-up time (months) } & ه18 & $19(47.50)$ & $20(47.62)$ & 0.935 & 0.892 \\
\hline & $\geq 18$ & $21(52.50)$ & $22(52.38)$ & & \\
\hline
\end{tabular}

\section{2 surgical methods}

Group A: the patients were in the prone position, chest and waist heighted with the body position pad, and the abdomen was suspended. Before surgery, the patients were treated with the closed reduction by over-extension traction in the prone position, and the surface projection of the fractured vertebral pedicle was located under the perspective of C-arm X-ray machine. Local anesthesia with $1 \%$ lidocaine was performed at the location of puncture point, and bilateral pedicle puncture was performed in both groups $A$ and $B$. Choose pedicle projection at $10 \mathrm{o}$ 'clock position in left and $2 \mathrm{o}$ 'clock position in right. Puncture path along the pedicle, oblique perspective puncture needle point reached fanterior about $1 / 3$, tip the pedicle is a perspective projection point and spines projection, pull out the needle core, to the bone drill work along the pipe screwing in vertebral bodies to distance fanterior $1 / 3$, pulls out the bone drill. To prepare bone cement and start injection when the bone cement is in the shape of wire drawing. The expected amount of bone cement infusion is $1 / 4$ of the volume of the vertebral body. However, when the bone cement spreads to $1 / 4$ to $1 / 5$ of the posterior edge of the vertebral body, the injection of bone cement should be stopped, or when it is found by fluoroscopy that the bone cement leaks to the bone, such as the intervertebral space, paravertebral, vein, etc. After the bone cement solidifies, rotate to pull out the puncture needle. Pressure dressing was applied at the puncture site and the operation was completed. The patients' vital signs and sensory movement of lower limbs were observed during the operation. One day after the operation, patients got out of bed and had conventional anti-osteoporosis treatment.

Group B: posture, preoperative closed reduction, anesthesia, puncture and bone drill enlargement were the same as group A. After pulling out the bone drill, the balloon was implanted along the working catheter. Under the monitoring of C-arm, it was found that the balloon was in A good position, then the balloon was gradually expanded by slowly injecting contrast agent, and the balloon was stopped when the height of the vertebral body was satisfied and recovered, and the contrast agent was withdrawn slowly, and the subsequent treatment was the same as that of group $\mathrm{A}$.

\section{3 surgical materials}

The instruments used in percutaneous kyphoplasty were manufactured by Shandong Guanlong company, and the bone cement used in the surgery was manufactured by Germany's heraeus company, polymethyl-methacrylate (PMMA). 
The operative time, intraoperative fluoroscopy times and injection of bone cement of the two groups were recorded. Visual analog score (VAS) and Oswestry disability index (ODI) in postoperative follow-up were recorded in the two groups. The height of the fractured vertebral body on the lateral X-ray (converted according to the marking scale) was measured before surgery, 1 day after surgery and 6 months after surgery in the two groups. The height of the fractured vertebral body = the distance between the center of the upper and lower endplate of the fractured vertebral body (the midpoint of the continuous front and rear edge of the endplate). The height of recovery of fractured vertebral body 1 day after surgery was calculated, and the height of loss of fractured vertebral body 6 months after surgery was calculated. Intraoperative and postoperative complications including the incidence of bone cement leakage, the incidence of nerve injury, puncture infection rate, and the incidence of pulmonary embolism were recorded. The incidence of adjacent vertebral fractures was followed up.

\section{5 statistical processing}

SPSS13.0 statistical software was used for statistical analysis. The significance level was set as 0.05 , and $P$ value $<0.05$ was considered statistically significant. Measurement data were expressed as mean \pm standard deviation $(x \pm s)$, mean comparison was performed by t test (bilateral), enumeration data were performed by chi-square test of four-lattice table, and gender comparison was performed by mann-whitney test.

\section{Results}

2.1 There were no adverse reactions of bone cement, iatrogenic spinal cord nerve injury, and complications of puncture infection in both groups A and B. During the follow-up period, there were 2 cases of adjacent vertebral body fracture in group A (percutaneous kyphoplasty group) and 3 cases of adjacent vertebral body fracture in group B (percutaneous kyphoplasty group), with no statistical difference between the two groups $(P>0.05)$. Typical cases are shown in Fig. 1,2.

2.2 The operative time and intraoperative fluoroscopy frequency of group A were less than that of group B, and the difference between the two groups was statistically significant $(P<0.05)$, while the difference in the injection amount of bone cement between group $A$ and group $B$ was not statistically significant $(P>0.05)$. There were 8 cases of bone cement leakage in group $A$, with a leakage rate of $20.00 \%$, and 7 cases of bone cement leakage in group $B$, with a leakage rate of $16.67 \%$. The difference between the two groups was not statistically significant $(P>0.05)$. The height of injured vertebrae in group A and group B increased by $2.91 \pm$ $1.49 \mathrm{~mm}$ and $3.38 \pm 1.72 \mathrm{~mm}$, respectively, compared with that before surgery. The difference between the two groups was not statistically significant $(P>0.05)$. The height loss of injured vertebrae was $0.97 \pm 0.36 \mathrm{~mm}$ and $1.14 \pm 0.45 \mathrm{~mm}$ during the follow-up 6 months after the operation, respectively, and the difference between the two groups was not statistically significant $(P>0.05)$. The total hospital expenses of patients in group A ( $1.78 \pm 0.15$ million RMB) were less than those in group B $(3.09 \pm 0.34$ million $R M B)$, and the difference between the two groups was statistically significant $(P<0.05$, as shown in Table 2$)$ 
Table 2

the perioperative and imaging indexes of the two groups

\begin{tabular}{|lllllllll|}
\hline Groups & $\mathbf{N}$ & $\begin{array}{l}\text { operative } \\
\text { time(min) }\end{array}$ & $\begin{array}{l}\text { intraoperative } \\
\text { fluoroscopy } \\
\text { frequency }\end{array}$ & $\begin{array}{l}\text { injection } \\
\text { amount of } \\
\text { bone } \\
\text { cement(ml) }\end{array}$ & $\begin{array}{l}\text { bone } \\
\text { cement } \\
\text { leakage(n) }\end{array}$ & $\begin{array}{l}\text { The height of } \\
\text { injured } \\
\text { vertebrae(mm) }\end{array}$ & $\begin{array}{l}\text { The lost } \\
\text { height of the } \\
\text { injured } \\
\text { vertebra was } \\
6 \text { months } \\
\text { after } \\
\text { surgery(mm) }\end{array}$ & $\begin{array}{l}\text { Total hospital } \\
\text { expenses(million } \\
\text { RMB) }\end{array}$ \\
\hline A & 40 & $\begin{array}{l}40.37 \pm \\
8.26\end{array}$ & $22.23 \pm 3.79$ & $5.67 \pm 1.73$ & 8 & $2.91 \pm 1.49$ & $0.97 \pm 0.36$ & $1.78 \pm 0.15$ \\
\hline B & 42 & $\begin{array}{l}46.74 \pm \\
9.58\end{array}$ & $27.96 \pm 5.71$ & $5.94 \pm 1.46$ & 7 & $3.38 \pm 1.72$ & $1.14 \pm 0.45$ & $3.09 \pm 0.34$ \\
\hline $\begin{array}{l}P- \\
\text { value }\end{array}$ & \begin{tabular}{l}
0.001 \\
\hline
\end{tabular} & 0.001 & 0.178 & 0.295 & 0.151 & 0.107 & 0.000 \\
\hline
\end{tabular}

VAS score and ODI score of patients in both groups A and B were lower than that of patients in the same group 1 day after surgery and 6 months after surgery, and the difference was statistically significant $(P<0) .05)$; VAS scores were compared 1 day after surgery and 6 months after surgery, $P>0.05$, the difference was not statistically significant. The ODI score was compared between 1 day after surgery and 6 months after surgery, $P<0.05$, the difference was statistically significant. VAS score and ODI score were compared between the two groups 1 day after surgery and 6 months after surgery, $P>0.05$, the difference was not statistically significant. See Table 3.

Table 3

VAS score and ODI score between the two groups

\begin{tabular}{|llllllll|}
\hline groups & $\mathbf{N}$ & $\begin{array}{l}\text { Preoperative } \\
\text { VAS score }\end{array}$ & $\begin{array}{l}\text { VAS score 1 day } \\
\text { after surgery }\end{array}$ & $\begin{array}{l}\text { VAS scores at } 6 \\
\text { months after surgery }\end{array}$ & $\begin{array}{l}\text { Preoperative } \\
\text { ODI }\end{array}$ & $\begin{array}{l}\text { ODI 1 day } \\
\text { after } \\
\text { surgery }\end{array}$ & $\begin{array}{l}\text { ODI was } 6 \\
\text { months after } \\
\text { surgery }\end{array}$ \\
\hline A & 40 & $6.63 \pm 1.57$ & $1.94 \pm 1.16$ & $1.97 \pm 1.45$ & $\begin{array}{l}84.57 \pm \\
12.93\end{array}$ & $\begin{array}{l}40.17 \pm \\
8.15\end{array}$ & $22.73 \pm 7.53$ \\
\hline B & 42 & $6.95 \pm 1.45$ & $2.13 \pm 1.64$ & $2.07 \pm 1.33$ & $85.62 \pm$ & $38.59 \pm$ & $21.38 \pm 6.47$ \\
\hline $\begin{array}{l}\text { P- } \\
\text { value }\end{array}$ & - & 0.332 & 0.594 & 0.463 & 0.533 & 0.326 & 0.401 \\
\hline
\end{tabular}

\section{Discuss}

Osteoporotic vertebral compression fracture is one of the common fractures in elderly patients. Compared with conservative treatment, long-term bedridden fracture may lead to serious complications and the permanent disability rate can reach $50 \%$. More and more scholars advocate the treatment of percutaneous vertebroplasty (kyphosis), 1,2), which can quickly relieve the pain in the back and restore the daily activities before the injury as soon as possible(3-5). Cement leakage is one of the common complications of vertebroplasty(6-7). For vertebral fracture, however, there are wall broken after osteoporotic vertebral compression fractures, percutaneous vertebral plasty or protruding after percutaneous vertebral plasty in the treatment, on the one hand, because of the bone cement may be damaged along the back wall crack to the spinal canal leakage, on the other hand, using a balloon expansion after the extrusion wall damage fracture block can lead to bone block back to the spinal canal, increase the risk of spinal cord, nerve damage. Therefore, some scholars believe that kyphoplasty is a relative contraindication for the treatment of osteoporotic vertebral compression fractures caused by posterior wall rupture(8-10). However, domestic scholars Dong zhiyong et al. (11). reported that the application of kyphoplasty in the treatment of vertebral posterior wall damage and osteoporotic fractures has not only achieved good efficacy, but also had good safety. Yang huilin et al (12). also achieved satisfactory clinical 
efficacy in the treatment of osteoporotic compression fractures with fracture of the perivertebral wall by PKP individualized surgical program. The results of this study showed that VAS score and vertebral body height in both groups A and B after surgery were significantly improved compared with that before surgery, with statistical significance, indicating that percutaneous vertebroplasty or percutaneous kyphoplasty had A definite clinical effect on osteoporotic compression fracture with posterior wall damage. At the same time, this study adopts the wall rupture after percutaneous vertebral plasty treatment vertebral compression fractures, bone cement leakage rate was $20.00 \%$, the use of the protruding after percutaneous vertebral plasty wall rupture after treatment vertebral compression fractures, bone cement leakage rate was $16.67 \%$, the incidence of leakage and the domestic and foreign literature on percutaneous vertebral bodies (convex) after keratoplasty in treatment of osteoporosis vertebral compression fractures complicated with bone cement leakage rate, and no case of spinal canal leakage, also did not appear adverse reactions, iatrogenic bone cement, puncture infection complications such as spinal cord injury. This study also shows that percutaneous vertebroplasty (kyphosis) is safe for the treatment of osteoporotic vertebral compression fractures caused by posterior wall rupture. VAS score, $\mathrm{ODI}$ score and bone cement leakage rate were not statistically significant between groups A and B. It is inconsistent with some literature reports(13-14). that PKP bone cement leakage rate is lower than PVP. Reasons for analysis: 1. Our expected injection of bone cement was $1 / 4$ of the volume of the vertebral body, which was inconsistent with most literatures and relatively low; 2. 2. Our puncture route is bilateral, which is more conducive to the diffusion of bone cement in the vertebra. Reduces the risk of cement leakage; 3 . We closely observed the diffusion of bone cement in the process of bone cement injection. If the bone cement reached $1 / 4$ to $1 / 5$ of the fractured vertebra, the injection of bone cement should be stopped immediately; this also reduced the risk of bone cement leakage. 4. Before surgery, we adopted the closed reduction with overextension traction in the prone position to restore the height of the vertebral body and reduce the risk of bone cement leakage.

When percutaneous vertebroplasty or percutaneous kyphoplasty is used for the treatment of osteoporotic vertebral compression fractures in the elderly with fractured posterior wall of the vertebral body, our experience in treatment should pay attention to the following points during the operation: 1 . The position of balloon implantation should be as close as possible to the anterior $1 / 3$ of the vertebra, away from the fracture and fracture of the vertebra, so as to prevent the compression of the posterior wall of the vertebra after balloon dilatation to the vertebral canal; 2 . Avoid excessive forced expansion of balloon and pursuit of recovery of injured vertebral height; 3 . The bone cement push rod should be as close as possible to the anterior wall of the vertebral body and away from the damaged posterior wall of the injured vertebral body; 4. Pay attention to the timing of bone cement injection, and carry out the injection when the bone cement is in the wire-drawing stage, so as to avoid the risk of uncontrolled bone cement leakage caused by too thin flow and diffusion of bone cement; 5. Proper amount of bone cement injection is needed; Studies(15). showed that when the volume of bone cement injection was about 1/4 of the volume of vertebral body, it could effectively relieve pain, restore the stiffness and strength of fractured vertebral body, and avoid the risk of cement leakage caused by excessive bone cement injection. 6 . The whole process of bone cement infusion should be carried out under the close dynamic monitoring of carm, and the infusion of bone cement should be stopped immediately when the leakage of bone cement to the surrounding wall of the vertebral body or the cement reaches $1 / 4$ to $1 / 5$ after the fracture of the vertebral body. 7 . Reduction of anterior prone position and hyperextension position; 8. Bilateral arch puncture was used to inject bone cement to avoid forced injection of bone cement to diffuse to the opposite side through unilateral puncture.

The surgical purpose of vertebroplasty is: on the one hand, to relieve the pain of the patient; on the other hand, to strengthen the fractured vertebra and enhance its stability. This operation stabilizes the fracture by injecting low-viscosity bone cement into the fractured vertebra and diffusing it into the trabecular space, thus increasing the mechanical strength and biomechanical stability of the anterior and middle column of the spine. The thermal effect of bone cement destroys the nerve endings in the fractured vertebral tissue and reduces or relives pain by reducing local inflammation. But the ability to correct kyphosis is limited. Kyphoplasty can partially restore the height of the anterior middle column of the fractured vertebra, improve the kyphoplasty deformity of the fractured vertebra, and reconstruct the biological force line of the spine by implantation of the expanded balloon. In this study, all patients were preoperatively treated with retroflexion traction and closed reduction, and the height of the injured vertebrae in the percutaneous kyphoplasty group was $2.91 \pm 1.49 \mathrm{~mm}$ higher than that before surgery, and the height of the injured vertebrae in the percutaneous kyphoplasty group was $6.38 \pm 1.72 \mathrm{~mm}$ higher than that before surgery, all of which partially improved the deformity of the fractured vertebra kyphoplasty. McKiernan F et al. (16). showed no correlation between the degree of recovery of fracture vertebral body height and the degree of postoperative pain relief. Another study(17). showed that the reduction of preoperatively overextension traction fractures in the prone position contributed to the recovery of vertebral height and the 
improvement of kyphosis deformity. The results of this study also confirmed that although the height recovery degree of the vertebral body in the PVP group was worse than that in the PKP group, the difference between the two groups was not statistically significant, which was inconsistent with some literature reports $[13,14]$ that the PKP vertebral body reduction effect was better than that of the PVP. The analysis may be related to the closed reduction through overextension traction in the prone position in all cases studied in this group before surgery.

In this study, it was also shown that the total cost of hospitalization in the PKP group was significantly higher than that in the PVP group, mainly because the price of consumables used in the PKP group was significantly higher than that in the PVP group.

Percutaneous vertebroplasty did not require balloon dilation during the operation, so the number of fluoroscopy was decreased and the operation time was shortened. Compared with kyphoplasty, the difference was statistically significant. Ji quan et al. (18) also showed that for osteoporotic vertebral compression fractures, if no correction is required for kyphosis deformity of the fracture, PVP has advantages over PKP, such as low cost, less fluoroscopy and short operation time, and corresponding selection is made in clinical according to patients' needs and different indications.

After percutaneous kyphoplasty for osteoporotic thoracolumbar fractures, the increased hardness of the vertebral body may lead to an increased incidence of adjacent vertebral body fractures. Domestic scholars Lin hua et al. (19) found that after vertebroplasty, the risk of adjacent vertebroplasty was increased, so they believed that the new adjacent vertebroplasty was closely related to vertebroplasty (kyphosis). In this study, there were 3 cases of adjacent vertebral fractures in the PKP group and 2 cases in the PVP group, and there was no significant difference in the incidence of adjacent vertebral fractures in the near and middle postoperative follow-up $(P>0.05)$.

\section{Conclusion}

In conclusion, both percutaneous vertebroplasty and percutaneous kyphoplasty for posterior wall breakage and osteoporotic vertebral compression fractures can achieve good analgesic and stabilizing effects, and there is no significant difference in the incidence of adjacent vertebral fractures in the near and middle postoperative complications. However, the former had lower cost, fewer intraoperative fluoroscopy times, shorter operative time, and did not increase the incidence of complications such as bone cement leakage. However, it remains to be seen whether a larger sample size will support the current conclusions or not.

\section{List Of Abbreviations}

\begin{tabular}{|ll|}
\hline Percutaneous kyphoplasty & (PKP) \\
\hline percutaneous vertebral plasty & (PVP) \\
\hline visual analog score & (VAS) \\
\hline Oswestry disability index & (ODI) \\
\hline osteoporotic vertebral compression will fracture & (OVCF) \\
\hline
\end{tabular}

\section{Declarations}

Ethics approval and consent to participate: This retrospective study was approved by the ethics committee of the first people's hospital of shuangliu district, Chengdu, Moreover, this study was also registered in the Chinese clinical trial registry with the registration number of ChiCTR1900028176.

Consent for publication: Not applicable

Availability of data and materials: The datasets generated and/or analysed during the current study are not publicly available due [REASON WHY DATA ARE NOT PUBLIC] but are available from the corresponding author on reasonable request.

Competing interests: The authors declare that they have no competing interests 
Funding: None

Author's contribution: Yong-sheng Gou collected data on PKP and PVP and was a major contributor to the manuscript. Hai-bo Li analyzed the data and was a major contributor to the revision of the manuscript; Bo-lin Fu and Zheng Che mainly provided these data, while Yue Hu translated, modified and reviewed the manuscript. All the authors read and approved the final manuscript.

Acknowledgements: Not applicable

\section{References}

1. Yoo JH, Moon SH, Ha YC, Lee DY, Gong HS, Park SY, Yang KH. Osteoporotic Fracture: 2015 Position Statement of the Korean Society for Bone and Mineral Research. J Bone Metab. 2015;22(4):175-81.

2. Willson T, Nelson SD, Newbold J, Nelson RE, LaFleur J. The clinical epidemiology of male osteoporosis: a review of the recent literature. Clin Epidemiol. 2015;7:65-76.

3. Expert Panels on Neurological. Imaging IR, Musculoskeletal I, Shah LM, Jennings JW, Kirsch CFE, Hohenwalter EJ, Beaman FD, Cassidy RC, Johnson MM, Kendi AT, et al: ACR Appropriateness Criteria((R)) Management of Vertebral Compression Fractures. J Am Coll Radiol 2018, 15(11S):347-64.

4. McConnell CT Jr, Wippold FJ 2nd, Ray CE Jr, Weissman BN, Angevine PD, Fries IB, Holly LT, Kapoor BS, Lorenz JM, Luchs JS, et al. ACR appropriateness criteria management of vertebral compression fractures. J Am Coll Radiol. 2014;11(8):757-63.

5. Bouza C, Lopez-Cuadrado T, Almendro N, Amate JM. Safety of balloon kyphoplasty in the treatment of osteoporotic vertebral compression fractures in Europe: a meta-analysis of randomized controlled trials. Eur Spine J. 2015;24(4):715-23.

6. He CJ, Liu GD. Comparison of the Efficacy and Safety of Bone-filling Mesh Container and Simple Percutaneous Balloon Kyphoplasty in the Treatment of Osteoporotic Vertebral Compression Fractures. Pain Physician. 2018;21(3):259-68.

7. Yang HL,Sun ZY,Zhang HT,et a1.How to prevent leaving" needle cast"or"cement tail"in vertebroplasty and kyphoplastyl J].Korean J Radiol,2012,13(5): .

8. Fan Xuehui,Dong Zhiyong,Huo Mingchang. Percutaneous Kyphoplasty in the Treatment of Serious Osteoporotic Vertebral Compression Fractures [J]. Journal of Applied Orthopaedics. 2015;21(11):965-8.

9. Huang Z, Wan S, Ning L, et al. Is unilateral kyphoplasty aseffective and safe as bilateral kyphoplasties for osteoporotic vertebral compression fractures? A meta- analysis[J]. ClinOrthop Relat Res. 2014;472(9):2833-42.

10. Capel C, Fichten A, Nicot B, et al. Should we fear cement leakage during kyphoplasty in percutaneous traumaticspine surgery? A single experience with 76 consecutive cases[J]. Neurochirurgie. 2014;60(6):293-8.

11. Zhiyong DONG, Xuehui FAN, Jiku YANG, et al. Safety and eficacy of percutaneous kyphoplasty in the treatment of osteoporotic vertebral compression fractures with posterior wall broken [J]. Chinese Journal of Bone Joint Surger. 2018;11(4):312-5.

12. Hui-lin YANG. NIU Guo-qi,WANG Gen-linã̄et a1.Kyphoplasty for the treatment of osteoporofic vertebral fractures with vertebral body wall incompetence [J]. Chin J Orthop. 2006;26(3):165-9.

13. Kai-chun, Lan. Comparative analysis and practice of percutaneous vertebroplasty and percutaneous kyphoplasty in the treatment of osteoporotic spinal compression fractures [J], Chinese and Foreign Medical Research,2019,17(3): 125-126.

14. Wen-xian HUANG, Song-bo DENG ZENG i $1 / 4^{2} \mathrm{i}$-xiang, et al., Analysis of clinical randomized controlled trials of PVP and PKP in the treatment of osteoporotic vertebral compression fractures [J], JOURNAL OF TAISHAN MEDICAL COLLEGE, 2019,40(1): 4144.

15. Nieuwenhuijse MJ, Bollen L, van Erkel AR, Dijkstra PD. Optimal intravertebral cement volume in percutaneous vertebroplasty for painful osteoporotic vertebral compression fractures. Spine (Phila Pa 1976). 2012;37(20):1747-55.

16. McKiernan F. Faciszewski T,Jensen R.Does vertebral height restoration achieved at vertebroplasty matter.9[J]. J Vasc Interv Radiol. 2005;16:973-9.

17. McKiernan F,Jensen R,Faciszewski T.The dynamic mobility of vertebral compression fractures[J].J Bone Miner Res.2003.18: 24-29.

18. Ji Quan ZHANG, Liang WANG, Qiang, et al., Eficacy of percutaneous vertebroplasty and percutaneous kyphoplasty for the treatment of painful osteoporotic vertebral compression fractures [J],CHIN J OSTEOPOROSIS\& BONE MINER 
RES,2013,6(I),28-33.

19. Lin Hua,Bao Li-hua, Zhu xiu-fen, et al. Analysis for new future of Vertebral body after percutanous vertebroplasty in patients with osteoporosis [J].CHIN J OS IEOPOROSIS\& BONE MINER RES,2008,1(1): 19-23.

\section{Figures}
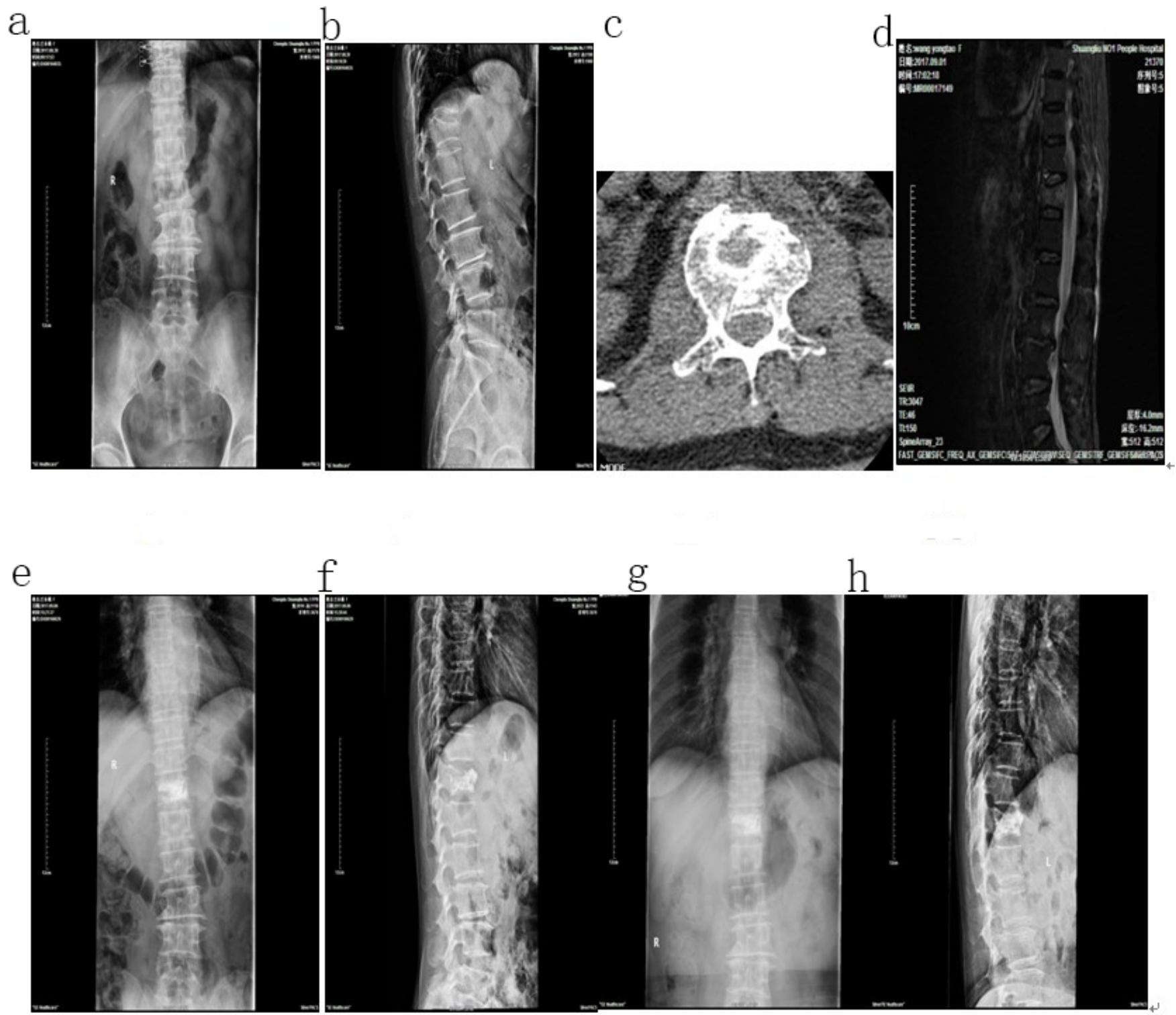

\section{Figure 1}

Group A patient, female, 68 years old, with a thoracic 12 osteoporotic vertebral compression fracture, underwent percutaneous vertebroplasty. a and b: preoperative positive and lateral X-ray showed compression fracture of the 12th thoracic vertebra, and the height of the anterior middle column was partially lost. c: preoperative CT showed fracture involving the posterior wall of the vertebral body. d: preoperative MRI (lipogram) showed high signal in the 12th thoracic vertebra. e,f: one day after surgery, positive and lateral X-ray showed that the bone cement was evenly distributed in the vertebral body. g,h: there was no significant change in the positive and lateral X-ray 6 months after the operation and 1 day after the operation. 


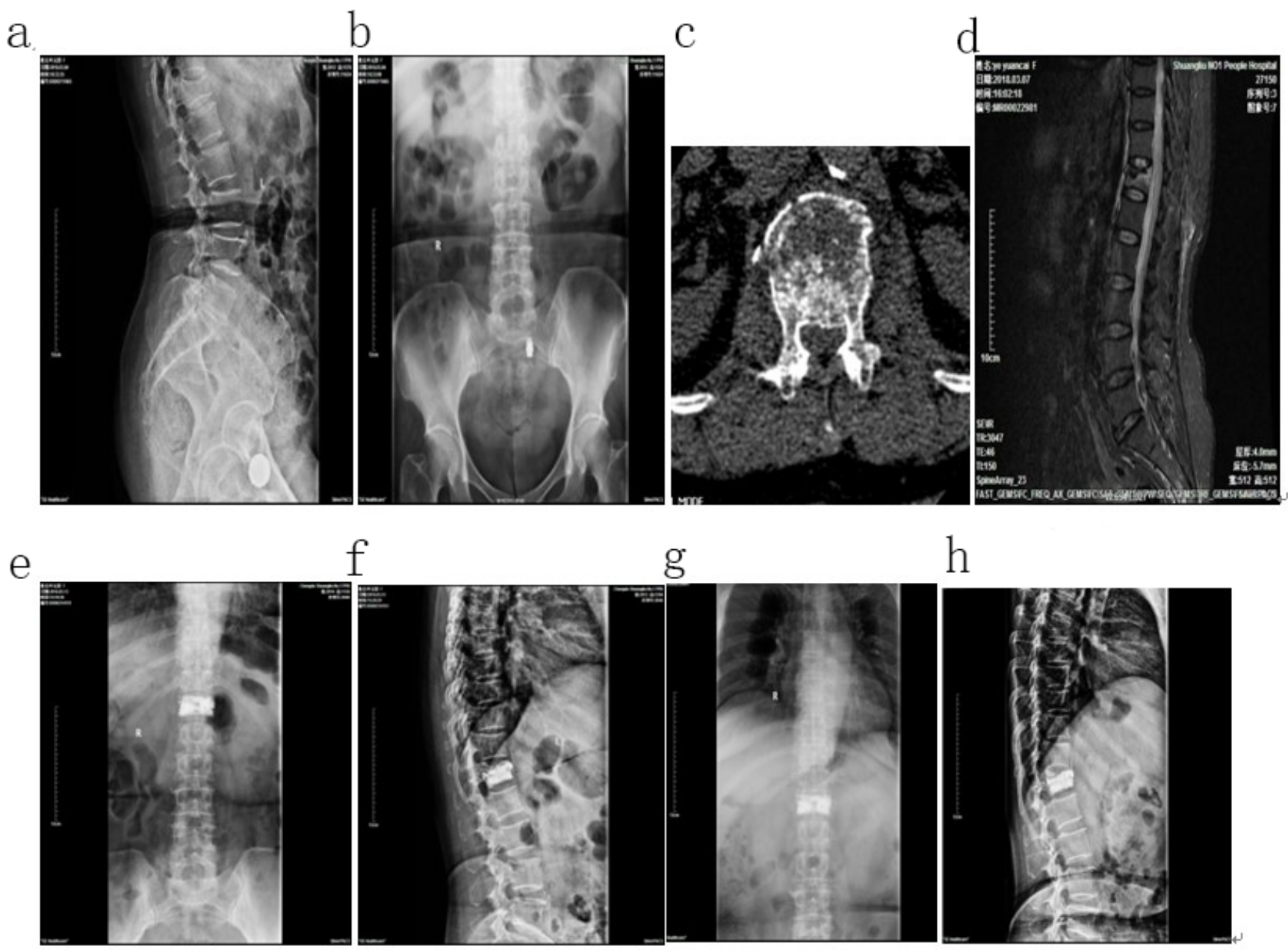

Figure 2

Group B Patient, female, 64 years old, with thoracic 12 osteoporotic vertebral compression fracture, underwent percutaneous kyphoplasty. a,b: preoperative positive and lateral X-ray showed compression fracture of the 12th thoracic vertebra, and the height of the anterior middle column was partially lost. c: preoperative CT showed fracture involving the posterior wall of the vertebral body. D: preoperative MRI (lipogram) showed high signal in the 12th thoracic vertebra. e,f:one day after the operation, positive and lateral X-ray showed that the bone cement was evenly distributed in the vertebral body. g,h: there was no significant change in the positive and lateral $\mathrm{X}$-ray 6 months after the operation and 1 day after the operation. 